\title{
Dedicated Education Unit: Improving graduating nursing students' preparedness for practice
}

\author{
Persephone Vargas,, Kimberly Dimino, Spencer Mullen \\ Department of Nursing, William Paterson University, United States
}

Received: August 27, 2020

Accepted: September 9, $2020 \quad$ Online Published: October 8, 2020

DOI: $10.5430 /$ jnep.v11n1p59

URL: https://doi.org/10.5430/jnep.v11n1p59

\begin{abstract}
Background and Objective: Majority of new graduate nurses are not adequately prepared to assume the dynamic and complex role of today's professional nurse. The Dedicated Education Unit (DEU) is a clinical teaching model developed in response to the limitations of traditional clinical model (TCM). The aim of the study is to examine the readiness for practice and level of confidence in clinical decision making among graduating nursing students in the DEU and compare it with the students in the TCM.

Methods: A pre-test/post-test design was used. The Casey-Fink Readiness for Practice was utilized in the pre and post-test surveys and the Nursing Anxiety and Self-Confidence in Clinical Decision-Making was used in the post test. Data was analyzed in aggregate and pre-test scores were compared to post-test scores at the cohort level using $t$-test.

Results: The pre-test results showed no significant difference between the DEU and TCM groups. However, the post-test results showed higher levels of readiness for practice and higher self-confidence and lower anxiety in clinical decision making among the DEU students.

Conclusions: The study provides evidence on the impact of the DEU in providing graduating nursing students with high quality clinical education to better prepare them for practice.
\end{abstract}

Key Words: Dedicated education unit, DEU, Clinical education, Readiness for practice, Clinical decision making

\section{INTRODUCTION}

As clinical nursing responsibilities continue to grow, clinical decision making become more complex. Leaders in nursing strive to identify empowering strategies that enhance the preparedness of new graduate nurses to practice as professional nurses. The Institute of Medicine's (IOM) 2010 report: The Future of Nursing: Leading Changes, Advancing Health 2010 Focus on Education identified that majority of new graduate nurses are not adequately prepared to assume the dynamic and complex role of today's professional nurse. ${ }^{[1]}$ In efforts to adhere to IOM's recommendations and prepare new graduate nurses for today's dynamic health care system, leaders in nursing must confront challenges associated with gaps between academia and real-world practice.

The expectations of newly graduate nurses have increased in the past several years; however, clinical teaching models have not kept pace with these changes. Traditional clinical models (TCM) of nursing education continue to be considered "the gold standard" of clinical nursing education. ${ }^{[2]}$ To date, there is lack of evidence identifying the effectiveness of this model as "best practice" with respect to student learning and patient safety. ${ }^{[3]}$ Students and faculty who participate in TCM often report limited time available for individual student teaching and supervision, being viewed by clinical staff as visitors, and lack of professional role development. ${ }^{[2]}$ The most concerning challenge of the TCM cited in the literature

*Correspondence: Persephone Vargas; Email: vargasp@ wpunj.edu; Address: Department of Nursing, William Paterson University, United States. 
is the inability of the faculty to effectively balance student learning and patient safety. ${ }^{[2]}$

\section{Literature review}

The DEU is an innovative clinical teaching model developed in response to the limitations of traditional clinical teaching models, the identified needs to better prepare students for practice and to improve and enhance academic-practice relationships. ${ }^{[1,4-6]}$ The DEUs are clinical sites in hospitals where baccalaureate prepared registered staff nurses, recognized for their clinical expertise, are trained and coached by academic faculty to serve as clinical instructors (CI) for nursing students. ${ }^{[7]}$ The DEU model optimizes the clinical teaching/learning environment by pairing two nursing students with one staff nurse who supports and educates students with applying learned clinical skills to real world practice. ${ }^{[4,6,7]}$ In this clinical teaching model, nurse faculty train experienced staff nurses to work with students in the clinical setting and provide ongoing coaching and support in the staff nurses' role as clinical instructors. ${ }^{[4,7]}$ Additionally, nurse faculty support students with meeting course objectives by challenging them to apply learned theory and critical thinking and clinical reasoning skills to problem solving in real world practice..$^{[4,7,8]}$

Studies have supported the increased level of satisfaction among students in the DEU. Students report that the DEU provided higher quality clinical learning experience and a more positive clinical learning environment. ${ }^{[6,9,10]}$ Students in the DEU perceived a sense of belonging in the unit and mentorship from the staff nurses. ${ }^{[6,11]}$ DEUs have also been identified to provide the students with more opportunities to learn communication, teamwork, time management, leadership and evidence-based practice. ${ }^{[6,9]}$ Improvement in the students' critical thinking and clinical judgment have been noted as a result of the DEU experience. ${ }^{[10,12]}$ DEUs enhance students' abilities to apply learned theory to real world practice, engage students in creative and meaningful clinical learning experiences and ease the transition from student to practicing professional nurse. ${ }^{[6,10,12]}$

Previous DEU studies have reinforced the improvement in the students' satisfaction with the teaching/learning environment, however, few studies have examined the DEU model beyond student satisfaction of their clinical learning experience and environment, and compared it to the TCM. Mulready-Shick et al. ${ }^{[10]}$ evaluated the clinical learning growth among students in the DEU and TCM and reported that DEU students perceived greater growth in clinical learning and in developing nursing knowledge, clinical skills, and ethical and professional behaviors. George et al. ${ }^{[13]}$ and Plemmons et al. ${ }^{[14]}$ evaluated the self-efficacy among nurs- ing students in the DEU and TCM. Both studies reported a more significant increase in perceived self-efficacy in the DEU students compared to TCM. These studies support the quality of the DEU as a clinical education model.

Scholarly publications on the DEU mostly include recommendations on how to implement them and how to identify and overcome obstacles, but few discuss quantitative student outcomes. In fact, a paucity of literature exists in regards to investigating the impact of the DEU in preparing graduating nursing students (GNS) for practice. The primary aim of the present study is to examine the readiness for practice and level of confidence in clinical decision making of GNS in the DEU and compare it with the students in the TCM.

\section{Methodology}

\subsection{Design and Participants}

The study utilized a pre/post-test research design. The participants were selected using a convenience sample of all nursing students in their final semester in a 4-year BSN program. The sample consisted of four cohorts of GNS BSN students $(\mathrm{N}=141)$.

For the final clinical experience, all participants were assigned to a DEU or TCM clinical experience. The DEU model consisted of one clinical faculty in charge of eight students. The DEU clinical faculty worked with staff nurse clinical instructors, selected by the unit managers, who received a minimum of four hours of orientation on DEU clinical teaching strategies. Each clinical instructor was assigned two students each. The DEU clinical faculty retained responsibility of oversight and evaluation of the students. The TCM consisted of a faculty-supervised clinical experience. The faculty was in charge of eight student nurses in a single clinical setting and was responsible for the students' clinical learning experience and evaluation. All participants, whether assigned to the DEU or TCM, completed a 14-week acute care clinical experience. The clinical experience included a 7-week (112 hours) rotation in a medical-surgical unit and a 7-week (112 hours) rotation in an acute care pediatric unit.

\subsection{Procedure}

Institutional Review Board approval was obtained from the university. The study was completed over four semesters from September 2017 to May 2019. For the pretest, all participants completed the Casey-Fink Readiness for Practice Survey on the first day of clinical experience. A second survey was conducted at the end of the clinical experience, during the last week of the semester. The second survey included the Casey-Fink Readiness for Practice Survey and the NASC-CDM(C Scale. All surveys were completed anonymously using pen and paper method. 
All survey analyses were completed using Statistical Package for Social Sciences Version 25. Descriptive analysis was used for the demographic variables and to determine the means of the Casey Fink Readiness for Practice Survey and NASC-CDM(C) subscales. Since the surveys were anonymous, data was analyzed in aggregate and pre-test scores were compared to post-test scores at the cohort, rather than the individual level. Pre and post test scores for the for the Casey Fink patient care assignment and four subscales and the NASC-CDM(C) three domains were compared for each cohort using independent samples $t$-test. A value of $p<.05$ was considered statistically significant.

\subsection{Survey Instruments}

Casey-Fink Readiness for Practice Survey. The survey consists of three sections which include demographic data and practicum information, the second section focuses on the student's comfort with clinical performance and the third section include open ended questions. ${ }^{[15]}$ This study focused on the second section of the survey, particularly the student's comfort level in managing multiple patient assignments and the 20-item question on their confidence in performing key nursing activities. The survey uses a 4-point Likert scale (1 $=$ strongly disagree, $2=$ disagree, $3=$ agree, $4=$ strongly agree) and identifies four domains of readiness for practice: clinical problem solving, professional identity, trials and tribulations, and learning techniques. ${ }^{[15]}$ Internal consistency was established on the original instrument, with an overall Cronbach's alpha of .69. ${ }^{[15]}$ For the current study, the overall Cronbach's alpha for the pretest was .714 and for the posttest .751 . The instrument was administered on paper and took approximately 15 minutes to complete.

Nursing Anxiety and Self-Confidence with Clinical DecisionMaking Scale (NASC-CDM()). The instrument measures participants' perceptions of their levels of self-confidence and anxiety during the process of clinical decision making. ${ }^{[16]}$ The NASC-CDM(C) is a 27-item questionnaire which uses a 6-point Likert type scale $(1=$ Not at all, $2=$ Just a little, $3=$ Somewhat, $4=$ Mostly, $5=$ Almost totally, $6=$ Totally). There are two subscales: anxiety $(\alpha=.96)$ and selfconfidence $(\alpha=.97)$ evaluating 3 domains: using resources to gather information and listening fully, using information to see the big picture and knowing and acting. ${ }^{[16]}$ For this study, the overall Cronbach's alpha was .837, anxiety subscale $\alpha=$ .96 and self-confidence subscale $\alpha=.97$. The instrument was administered on paper and took approximately 15 minutes to complete.

\section{Results}

\subsection{Sample characteristics}

The total sample $(\mathrm{N}=141)$ consisted of 64 DEU students and 77 TCM students. The breakdown of GNS per semester are as follows: Fall $2017=32$, Spring $2018=42$, Fall $2018=$ 25 , Spring $2019=42$. The participants were mostly female. In the DEU group, $79.7 \%(\mathrm{n}=51)$ were female and $20.3 \%$ $(n=13)$ were male. In the traditional clinical group, $79.25 \%$ $(n=65)$ were female and $19.5 \%(n=15)$ were male, one participant did not indicate their gender.

The mean age of the students in the DEU was 22.58 (range $20-36, \mathrm{SD}=2.58$, range) and for the traditional clinical group, 22.97 (range $=20-45, \mathrm{SD}=3.73$, range). Using an independent $t$-test, there was no significant difference between the ages of the students in the two clinical groups.

\subsection{Casey-Fink Readiness for Practice Survey}

The Casey-Fink Readiness for Practice Survey was conducted at the beginning and at the end of the semester. Results of the students' confidence level in the management of patient assignments are presented below and in Table 1 . Results of the four subscales of the survey are also presented below and in Table 2 .

\subsubsection{Management of Patient Care Assignments}

In comparing the pre-test confidence level in managing patient care assignments between the DEU and TCM groups, there were no statistically significant difference in the confidence level in caring for $2(p=.49), 3(p=.42)$, or 4 ( $p=$ $.98)$ patients. In the post test survey, there was no statistically significant difference in the confidence level in managing patient care assignment of 2 patients $(p=.23)$ between the two groups. However, the confidence level in managing 3 patients in the DEU group $(\mathrm{m}=4.39, \mathrm{sd}=.68)$ compared to the TCM group $(\mathrm{m}=4.14, \mathrm{sd}=.70)$ was significantly higher $(t(139)=2.14, p=.034)$. The confidence level in managing 4 patients in the DEU group $(\mathrm{m}=3.56, \mathrm{sd}=1.05)$ compared to the TCM group $(\mathrm{m}=2.99, \mathrm{sd}=.90)$ was significantly higher $(t(139)=3.50, p=.001)$.

\subsubsection{Clinical Problem-Solving Domain}

The clinical problem solving domain included questions on the student's confidence and comfort level in the following activities: communicating with physicians, ability to problem solve, use of current evidence to make clinical decisions, communicating and coordinating care with interdisciplinary team members, knowing what to do for a dying patient, taking action to action to solve problems and identifying actual or potential safety risks to my patients. ${ }^{[15]}$ The summed score of the means for each in this domain was calculated for each clinical group. An independent $t$-test was used to compare 
the means of the clinical problem-solving domain between the two clinical groups. In the pre-test survey, there was no significant difference in the clinical problem-solving domain scores between the two clinical groups $(p=.33)$. In the post-test survey, the DEU group $(m=23.02, \mathrm{sd}=2.91)$ had a statistically significant higher mean than the TCM group (m $=21.49, \mathrm{sd}=2.83$ ) in the clinical problem solving domain $(t(139)=3.12, p=.002)$.

Table 1. Confidence level in patient assignment

\begin{tabular}{|c|c|c|c|c|c|}
\hline Confidence & Level in Patient Assignment & $\begin{array}{l}\text { TCM } \\
\text { M (SD) }\end{array}$ & $\begin{array}{l}\text { DEU } \\
\text { M (SD) }\end{array}$ & $t$ & $p$ \\
\hline \multirow[t]{2}{*}{2 patients } & Pre-test & $4.37(.69)$ & $4.28(.79)$ & -.70 & .49 \\
\hline & Post-test & $4.73(.50)$ & $4.83(.46)$ & 1.20 & .23 \\
\hline \multirow[t]{2}{*}{3 patients } & Pre-test & $3.54(.92)$ & $3.41(1.02)$ & -.81 & .42 \\
\hline & Post-test & $4.14(.70)$ & $4.39(.68)$ & 2.14 & $.034 *$ \\
\hline \multirow[t]{2}{*}{4 patients } & Pre-test & $2.45(1.14)$ & $2.45(1.04)$ & .03 & .98 \\
\hline & Post-test & $2.99(.90)$ & $3.56(1.05)$ & 3.5 & $.001 *$ \\
\hline
\end{tabular}

*denotes findings that reach statistical significance

Table 2. Casey Fink Readiness for Practice Subscale results

\begin{tabular}{|c|c|c|c|c|}
\hline Casey-Fink Subscales & $\begin{array}{l}\text { TCM } \\
\text { M (SD) }\end{array}$ & $\begin{array}{l}\text { DEU } \\
\text { M (SD) }\end{array}$ & $t$ & $p$ \\
\hline \multicolumn{5}{|l|}{ Clinical Problem Solving } \\
\hline Pre-test & $20.18(2.87)$ & $19.74(2.37)$ & -.98 & .33 \\
\hline Post-test & $21.49(2.83)$ & $23.02(2.91)$ & 3.12 & $.002^{*}$ \\
\hline \multicolumn{5}{|l|}{ Learning Techniques } \\
\hline Pre-test & $5.13(1.38)$ & $5.20(1.16)$ & .32 & .75 \\
\hline Post-test & $4.86(1.52)$ & $5.70(1.22)$ & 3.60 & $.000^{*}$ \\
\hline \multicolumn{5}{|l|}{ Professional Identity } \\
\hline Pre-test & $16.16(2.81)$ & $17.08(1.87)$ & -1.01 & .31 \\
\hline Post-test & $15.74(1.82)$ & $18.47(1.67)$ & 4.62 & $.000^{*}$ \\
\hline \multicolumn{5}{|l|}{ Trials and Tribulations } \\
\hline Pre-test & $13.80(1.83)$ & $15.72(1.86)$ & .12 & .90 \\
\hline Post-test & $13.84(2.08)$ & $16.50(1.85)$ & 2.75 & $.007^{*}$ \\
\hline
\end{tabular}

*denotes findings that reach statistical significance

\subsubsection{Learning Techniques Domain}

The learning technique domain included questions on the use of simulation and reflective writing to prepare the student for practice and to improve clinical decision making skills. ${ }^{[15]}$ The summed score of the means for each item in this domain was calculated for each clinical group. An independent $t$-test was used to compare the means of the learning technique domain between the two clinical groups. In the pre-test survey, there was no statistically significant difference in their learning techniques between the two groups $(p=.75)$. In the post-test survey, the DEU group $(m=5.70, \mathrm{sd}=1.22)$ had a statistically significant higher mean than the TCM group (m $=24.86, \mathrm{sd}=1.52)$ in the learning techniques domain $(t(139)$ $=3.60, p=.000)$.

\subsubsection{Professional Identity Domain}

The professional identity domain included questions on the student's confidence and comfort level on: communicating with patients and their families, asking for help, satisfaction with choosing nursing as a career and readiness to assume RN role. ${ }^{[15]}$ The summed score of the means for each item in this domain was calculated for each clinical group. An independent $t$-test was used to compare the means of the professional identity domain between the two clinical groups. In the pre-test survey, there was no statistically significant difference in their professional identity between the two groups $(p=.300)$. In the post-test survey, the DEU group $(m=18.47$, $\mathrm{sd}=1.67$ ) had a statistically significant higher mean than the TCM group $(\mathrm{m}=17.08, \mathrm{sd}=1.87)$ in the professional identity domain $(t(139)=4.62, p=.000)$.

\subsubsection{Trials and Tribulations Domain}

The trials and tribulations domain included questions on the student's comfort level on delegating tasks to the nursing assistant and the student's difficulty in: documenting in the electronic medical record, prioritizing care, recognizing changes in the patient's condition and in dealing with ethical issues. ${ }^{[15]}$ The summed score of the means for each 
item in this domain was calculated for each clinical group. An independent $t$-test was used to compare the means of the trials and tribulations domain between the two clinical groups. In the pre-test survey, there was no statistically significant difference in the trials and tribulations between the 2 groups $(p=.90)$. In the post-test survey, the DEU group (m $=16.60, \mathrm{sd}=1.85)$ had a statistically significant higher mean than the TCM group $(\mathrm{m}=15.72, \mathrm{sd}=1.86)$ in the trials and tribulations domain $(t(139)=2.75, p=.007)$.

\subsection{NASC-CDM(C) Survey}

The NASC-CDM(C) survey was completed by the participants at the end of their final clinical experience. The results of the NASC-CDM(C Survey using the three domains are presented below and in Table 3.

Table 3. NASC-CDM(C)

\begin{tabular}{|c|c|c|c|c|}
\hline $\begin{array}{l}\text { NASC-CDM } \\
\text { Domains }\end{array}$ & $\begin{array}{l}\text { TCM } \\
\text { M (SD) }\end{array}$ & $\begin{array}{l}\text { DEU } \\
\text { M (SD) }\end{array}$ & $t$ & $p$ \\
\hline \multicolumn{5}{|l|}{ Domain1 } \\
\hline Anxiety & 27. 23 (10.27) & 21.94 (7.37) & -3.42 & $.001 *$ \\
\hline Self-Confidence & $60.08(10.21)$ & $65.26(9.62)$ & 3.04 & $.003 *$ \\
\hline \multicolumn{5}{|l|}{ Domain 2} \\
\hline Anxiety & $16.64(5.56)$ & $14.48(5.18)$ & -2.32 & $.022 *$ \\
\hline Self-Confidence & $29.97(5.86)$ & 33.13 (5.73) & 3.14 & $.002 *$ \\
\hline \multicolumn{5}{|l|}{ Domain 3} \\
\hline Anxiety & $17.00(4.78)$ & $14.43(4.80)$ & -3.17 & $.002 *$ \\
\hline Self- Confidence & 29.49 (6.03) & 32.67 (5.95) & 3.10 & $.002 *$ \\
\hline
\end{tabular}

*denotes findings that reach statistical significance

Domain 1 - Using resources to gather information and listening fully included items such as communication, assessment and use of evidence-based practice. ${ }^{[16]}$ An independent $t$-test was conducted to determine the difference in anxiety level and self-confidence between the two clinical groups in using resources to gather information and listening fully. For Domain 1, the DEU students $(m=21.94, s d=7.37)$ had a significantly lower anxiety level than the students in the TCM group $(\mathrm{m}=27.23 \mathrm{sd}=10.27),(t(139)=-3.42, p=.001)$. The DEU group $(\mathrm{m}=365.26$, $\mathrm{sd}=9.62)$ had a significantly higher self confidence level than the TCM group $(m=60.08$, $\mathrm{sd}=10.21),(t(139)=3.04, p=.003)$.

Domain 2 - Using information to see the big picture included items such as synthesizing knowledge from nursing and other related disciplines to make decisions, and seeing the full clinical picture. ${ }^{[16]}$ An independent $t$-test was conducted to determine the difference in anxiety level and self-confidence between the two clinical groups in using information to see the big picture. For Domain 2, the DEU students had a statistically lower anxiety level $(\mathrm{m}=14.48 \mathrm{sd}=5.18)$ compared to the students in the TCM group $(\mathrm{m}=16.64, \mathrm{sd}=5.55), t(139)$ $=-2.32, p=.022$. The DEU students had a significantly higher self-confidence $(m=33.13, \mathrm{sd}=5.73)$ compared to the students in the TCM group $(\mathrm{m}=29.97, \mathrm{sd}=5.86), t(139)$ $=3.14, p=.002$ ).

Domain 3 - Knowing and acting included items such as us- ing resources to effectively analyze situations and choosing the best options in making a decision. ${ }^{[16]}$ An independent $t$-test was conducted to determine the difference between the two clinical groups in knowing and acting. For Domain 3, the DEU students had a lower anxiety level $(\mathrm{m}=14.43$, $\mathrm{sd}=$ 4.80) compared to the students in the TCM group $(\mathrm{m}=17.00$, $s d=4.76), t(139)=-3.17, p=.002$. The DEU students had a significantly higher self-confidence $(\mathrm{m}=33.13, \mathrm{sd}=5.73)$ compared to the students in the TCM $(\mathrm{m}=29.97, \mathrm{sd}=5.86)$, $t(139)=-3.17, p=.002$.

\section{Discussion}

The primary aim of the study was to determine the readiness for practice and level of confidence of GNS in the DEU and compare it with the students in the TCM. The results of the study highlight the significant difference in the readiness for practice and level of confidence between GNS in the DEU and TCM. It is important to note that the students in both clinical groups had similar readiness for practice and level of confidence in the pre-test survey. Both clinical groups had similar clinical hours in similar clinical settings. At the end of the clinical experience, both DEU and TCM students showed improvement in their subscale scores for both the Casey-Fink Readiness for Practice Survey and NASC-CDM(C). However, the DEU students showed significantly higher readiness for practice and level of confidence compared to the TCM students. 
The impact of the DEU in the GNS's ability to manage multiple patients was clearly identified in this study. At the end of the clinical experience, both groups had similar levels of comfort managing two patients. However, DEU students reported being more comfortable in managing three patients. The difference became more significant when managing four patients. The 4-patient caseload item may have the greatest validity in differentiating between students with higher versus lower readiness to manage the typical patient caseloads seen in practice settings. ${ }^{[15]}$ In the DEU, the students are exposed to the real-world activities of the staff nurse. This allows them to be able to successfully manage more than the 1 or 2 patients TCM students usually have.

Readiness for practice and confidence levels, as measured by the Casey-Fink Readiness for Practice Survey and NASC$\mathrm{CDM}\left({ }^{-}\right.$, in all subscales, were higher among the DEU students. While the anxiety level in all subscales, as measured by the NASC-CDMCC, was lower in the DEU students. Graduating nursing students who lack confidence and competence are at great risk for experiencing stress and difficulty transitioning into their new role. ${ }^{[17-20]}$ Specific reasons for GNS stress include self-perceived lack of understanding of their future professional role, challenges in making safe and sound clinical decisions, difficulties with organization and prioritization and lack of experience with assimilation into the work environment. ${ }^{[21-24]}$ Lack of confidence can impact patient care and impede the transition of GNS into the role of a professional nurse. ${ }^{[1,5,17,25]}$ Studies have shown that newly graduated nurses who felt unprepared, experienced difficulty transitioning into the role of professional nurse and were less likely to thrive. ${ }^{[19]}$ Students who have DEU experience have demonstrated increased critical thinking, confidence and self-efficacy and decrease in anxiety up to 12 months after graduation. ${ }^{[26]}$ This supports the role of the DEU in

\section{REFERENCES}

[1] Institute of Medicine (IOM). The future of nursing: Leading change, advancing health. 2010. Available from: http://books.nap.edu/ openbook. php?record_id=12956\&page=R1

[2] Luhanga F. The traditional-faculty supervised teaching model: Nursing faculty and clinical instructors' perspectives. Journal of Nursing Education and Practice. 2018; 8(6): 124-137. https ://doi.org/ 10.5430/jnep. v8n6p124

[3] Jayasekara R, Smith C, Hall C, et al. The effectiveness of clinical education models for undergraduate nursing programs: A systematic review. Nurse Education in Practice. 2018; 29: 116-126. PMid:29272736 https : //doi.org/10.1016/j.nepr.2017.12 .006

[4] Edgecombe, et al. Dedicated education units: a new concept for easing the new graduate nurses' transition to practice.

Participating in the collaborative academic-practice partnership of the DEU provides an easier transition for newly graduated nursing students to develop into to the role of a competent nurse. ${ }^{[13]}$ The DEU model helps students engage in creative and meaningful clinical learning experiences where gaps between theory and real-world practice can be better identified, addressed, and bridged. ${ }^{[12]}$ This allows the DEU students to participate more in relevant nursing activities that strengthen their clinical decision making and professional behaviors.

\section{Limitations of the Study}

Limitations of this study include the use of convenience sampling in participant selection. The participants were not randomly selected and were informed that they were participating in a study to evaluate readiness for practice. The study was conducted at one BSN program with an established DEU and may limit generalizability.

\section{Conclusion}

The study provides substantial evidence on the impact of the DEU in providing GNS with high quality clinical education to better prepare them for practice. Readiness for practice, including higher level of confidence in the management of multiple patient assignments, higher self- confidence and lower anxiety level in clinical decision making was more evident among the DEU students compared to TCM students. The use of a DEU as the final clinical experience for GNS will promote confidence in the newly graduate nurses and support a successfully transition to the role of a professional nurse.

\section{CONFLICTS OF INTEREST Disclosure}

The authors declare that there is no conflict of interest. clinical teaching and learning. Contemporary Nurse. 1999; 8: 166171. PMid:11141789 https://doi.org/10.5172/conu.1999. 8.4.166

[5] Dapremont J, Lee S. Partnering to educate: Dedicated education units. Nurse Education in Practice. 2013; 13(5): 335-337. PMid:23507074 https://doi.org/10.1016/j.nepr.2013.02.015

[6] Nishioka V, Coe M T, Hanita M, et al. Dedicated Education Unit: Nurse Perspectives on Their Clinical Teaching Role. Nursing Education Perspectives. 2014; 35(5): 294-300. PMid:25291924 https : //doi.org/10.5480/14-1381

[7] Moscato S, Miller J, Logsdon K, et al. Dedicated education unit: an innovative clinical partner education model. Nursing Outlook. 2007; 55(1): 31-37. PMid:17289465 https ://doi.org/10.1016/j . ou tlook.2006.11.001 
[8] Rhodes M, Meyers C, Underhill M. Evaluation outcomes of a dedicated education unit in a baccalaureate nursing program. Journal of Professional Nursing. 2012; 28(4): 223-230. PMid:22818192 https://doi.org/10.1016/j.profnurs.2011.11.019

[9] Freundl M, Anthony M, Johnson B, et al. A dedicated education unit VA Medical Centers and baccalaureate nursing programs partnership model. Journal of Professional Nursing. 2012; 28(6): 344-350. PMid:23158197 https : //doi.org/10.1016/j.profnurs. 201 2.05 .008

[10] Mulready-Shick J, Flanagan K, Banister G, et al. Evaluating Dedicated Education Units for Clinical Education Quality. Journal of Nursing Education. 2013; 52(11): 606-614. PMid:24127181 https : //doi .org/10.3928/01484834-20131014-07

[11] Jeffries P, Rose L, Belcher A, et al. A clinical academic practice partnership: a clinical education redesign. Journal of Professional Nursing. 2013; 29 (3): 128-136. PMid:23706965 https : //doi.org/10.1016/j.profnurs.2012.04.013

[12] Schecter R, Gallagher J, Ryan M. Enhancing Baccalaureate Nursing Students' Perception of and Confidence During an Alternative Dedicated Education Unit Experience: A Pilot Study. Journal for Nurses in Professional Development. 2017; 33(3): 120-126. PMid:28471993 https://doi.org/10.1097/NND.0000000000000338

[13] George L, Locasto L, Pyo K, et al. Effect of the dedicated education unit on nursing student self-efficacy: A quasi-experimental research study. Nurse Education in Practice. 2017; 2348-53.

[14] Plemmons C, Clark M, Feng D. Comparing student clinical selfefficacy and team process outcomes for a DEU, blended, and traditional clinical setting: A quasi experimental research study. Nurse Education Today. 2018; 62: 107-111. PMid:29306749 https : //doi.org/10.1016/j.nedt.2017.12.029

[15] Casey K, Fink R, Jaynes C, et al. Readiness for practice: the senior practicum experience. Journal of Nursing Education. 2011; 50(11): 646-652. PMid:21846072 https ://doi.org/10.3928/ 01484834-20110817-03

[16] White KA. Development and validation of a tool to measure selfconfidence and anxiety in nursing students during clinical decision making. Journal of Nursing Education. 2014; (53)1: 14-22.

[17] Benner P. Educating nurses: A call for radical transformation (First edition.). San Francisco: Jossey-Bass; 2010.
[18] Frögéli E, Rudman A, Ljótsson B, et al. Preventing stress-related ill health among newly registered nurses by supporting engagement in proactive behaviors: development and feasibility testing of a behavior change intervention. Pilot and Feasibility Studies. 2018; 4: 28 PMid:29321942 https://doi.org/10.1186/s40814-017-021 9-7

[19] Hickerson K, Taylor L, Terhaar M. The preparation-practice gap: an integrative literature review. Journal of Continuing Education in Nursing. 2016; 47(1): 17-23. PMid:26790493 https ://doi .org/ 10.3928/00220124-20151230-06

[20] Ortiz J. New graduate nurses' experiences about lack of professional confidence. Nursing Education in Practice. 2016; 29: 19-24. PMid:27428687 https ://doi.org/10.1016/j.nepr.2016.04 .001

[21] American Association of Colleges of Nursing (AACN). Advancing Health Care Transformation: A New Era for Academic Nursing. 2016. Available from: http://www . aacnnursing.org/Portal s/42/Publications/AACN-New-Era-Report.pdf

[22] Casey K, Fink R, Krugman M, et al. The graduate nurse experience. Journal of Nursing Administration. 2004; 34(6): 303-311. PMid:15190226 https : //doi .org/10.1097/00005110-20040 6000-00010

[23] Halpin Y, Terry LM, Curzio J. A longitudinal, mixed methods investigation of newly qualified nurses' workplace stressors and stress experiences during transition. Journal of Advanced Nursing. 2017; 73(11): 2577-2586. PMid:28543602 https://doi.org/10.111 $1 /$ jan. 13344

[24] Tong V, Epeneter B. A Comparative Study of Newly Licensed Registered Nurses' Stressors: 2003 and 2015. Journal of Continuing Education in Nursing. 2018; 49(3): 132-140. PMid:29498401 https://doi.org/10.3928/00220124-20180219-08

[25] Spector N, Blegen M, Silvestre J, et al. Transition to Practice Study in Hospital Settings. Dakota Nurse Connection. 2015; 13(2): 8-28.

[26] Vnenchak K, Sperling M, Kelley K, et al. Dedicated education unit improving critical thinking and anxiety. Journal for Nurses in Professional Development. 2019; 35(6): 317-323. PMid:31652171 https://doi.org/10.1097/NND.0000000000000586 